\title{
A REVIEW OF DUAL-MOTOR SYSTEM AND METHODS FOR CHARGING BATTERIES OF AN E-VEHICLE
}

\author{
Lokesh M. Giripunje ${ }^{1}$, Vipul Kumar Singh², Govind Suryakant Kendre ${ }^{3}$ \\ ${ }^{1}$ Assistant Professor, ${ }^{2,3}$ Students
}

Article DOI: https://doi.org/10.36713/epra7181

DOI No: 10.36713/epra7181

\begin{abstract}
The use of electric cars has the potential to reduce transportation-related pollution. Their adoption has been hampered by the lack of and/or high cost of charging facilities. As a result, small on-board chargers are often used as the main charging system in cars. We know that batteries can be charged in two ways: conductive and inductive. Here we are proposing a dual motor based charging. We know that when we power a motor with electricity, the electrical energy is converted into mechanical energy and vice versa. Here we are using rear motors for the movement of our car. This movement is used by front motors for producing electrical signals again. Of course the power used by the rear motor and the power generated by the front motor is not the same. There is a significant difference; if we assume that the power used by the rear motor is $100 \%$, the power generated by the front motor is between 30 and 60 percent. This generated power is now being used to charge the battery, and the battery will charge while driving the car. This is the main idea behind this technology.
\end{abstract}

KEYWORDS - E-vehicle, Efficiency of E-vehicle, Dual motor system, Efficient Charging, \& EV

\subsection{PROBLEM STATEMENT}

There're so many e-vehicle manufacturers like Tesla, Tata, etc. The issue with every e-vehicle is that the output on a single charge is insufficient. Charging stations are the most problematic issue in developing countries such as India. The charging time is a major issue with Li-ion batteries and all other batteries. The charging time for batteries is much longer than the output time. A large amount of electricity is required at the charging point, which is generated by coal. This is the most significant disadvantage because coal emits more pollution than diesel or gasoline-powered vehicles.

\subsection{INTRODUCTION}

Concerns over carbon dioxide emissions, greenhouse gas emissions, and the rapid depletion of fossil fuels have heightened the need to develop and implement modern eco-friendly, long-term alternatives to internal combustion engine (ICE) vehicles. The issue with every e-vehicle is that the output on a single charge is insufficient. The most pressing issue in developing countries such as India is the lack of charging stations or charging points. Another issue with using a Lithium-ion (Li-ion) battery or any other battery is that they take an inordinate amount of time to charge. The charging time for batteries is significantly longer than the output or operating hours provided by the e-vehicle. Furthermore, the e-vehicle consumes a large amount of electricity, and the charging point typically uses coal to produce electricity, which is another disadvantage because using coal causes excessive pollution when compared to diesel or petrol engine vehicles. This is where papers suggesting a dual-inverter drive to charge directly from a singlephase AC grid at power levels higher than current onboard chargers may fail to make an impact. Integrating 


\section{SJIF Impact Factor 2021: 8.013| ISI I.F.Value:1.241| Journal DOI: 10.36713/epra2016 ISSN: 2455-7838(Online) EPRA International Journal of Research and Development (IJRD)

local power production, such as renewable energy sources (RESs), into the EV charging grid is one effective way to mitigate the impact. Currently, evehicle motors are underutilized for a variety of reasons, including low efficiency of the motor and batteries; a significant amount of time is required for charging batteries; and a scarcity of battery charging stations. As a result, e-vehicles can only be driven for short distances, indicating that there is room for improvement in the operation and manufacturing of evehicles.

As a result, there is a need in the art to develop an efficient, simple, and cost-effective system and method for e-vehicles to efficiently charge e-vehicle batteries while driving, thereby reducing the frequency of charging required as well as the charging time of the e-vehicle batteries.

\section{LITERATURE REVIEW}

Lithium-ion batteries have a few advantages over other types of energy storage systems, such as high energy and_power efficiency, reduced memory effect and resulting performance loss, this type of battery is the ideal candidate for the field of electric vehicles.

1. The main charging methods are as follows:

Constant Current- Constant Voltage(CC-CV) approach employs both an initial constant current and a final constant voltage. The charging phase begins with a steady current and continues until the cut-off voltage, is achieved. When the current drops to between 3 and $5 \%$ of the rated current, the battery is fully charged.

An alternative approach to the above method, i.e., the charging time is broken down into five stages. The charging current is set to a constant threshold value at each stage has also been proposed. During charging, the battery's voltage rises, and as it exceeds the predefined maximum voltage, the stage number rises, and a new charging current set value is added.

In pulse charging method technique, the charging current is pumped into the battery in the form of pulses, allowing the ions to disperse and neutralise. The charging rate is determined by the average current. It can be adjusted by changing the pulse duration.

The problem with these procedures is that they do not account for the ageing mechanism and the side reactions that occur inside the battery over a period of time. Considering this, in order to minimise the ageing in a given charge period it has been proposed to measure the volume of battery ageing. The problem with the mentioned approach is that the model would become complex and almost impossible to implement. 2. Besides this, an integrated charging concept has also been proposed to overcome the disadvantages of on- board chargers. The suggested method for storing energy is to use a traditional single inverter and motor drivetrain. The network can be linked between the two neutral points of the motor in the case of a split-phase drive-train. The planned topology includes a dualinverter drivetrain for traction, as well as an external passive filter stage. If necessary, the rectifier may be attached directly or with an external isolation transformer to isolate it from the power source for safety reasons.

As KVL is applied through the dual-inverter and the grid (losses excluded), there is a higher grid voltage compatibility which is due to the fact that the voltage provided by the converter is the sum of all the half bridges as is the proposed topology of the grid.

3. To address the above problems, an EV technology battery management system (BMS) has also been proposed, which includes a data acquisition unit, a contact unit, battery location estimation model, thermal control and high voltage management which helps in battery life improvement.

4. Charging using solar energy has also been proposed. There are two Photo-voltaic charging models, namely the PV-grid and PV-standalone. The MPPT dc-dc converter, which is usually built on the buck-boost or boost topology, is used to extract as much power as possible from the PV series. The problem with PV grid is that with there are a lot of power conversion stages because the energy harvested by the solar panels is primarily direct current (DC). This must be changed to AC current before it can be used to charge electric vehicles or other automotive equipment.

In order to solve the problem PV-standalone model has been proposed where the EV would be charged exclusively with PV power, i.e. without using the electric grid. With PV-standalone model as well there comes a problem of overloading. To overcome this an adaptive PV-standalone device can be used to make the most use of usable solar energy.

\section{PROPOSED SYSTEM}

The proposed system tries to fulfill the following objectives:

- A dual-motor system and method for charging an e-vehicle's batteries with an efficient charging mechanism that charges the batteries even while the e-vehicle is in motion.

- Reduce the frequency of external charging requirements as well as the charging time of the battery.

- Dual-motor system and method for charging batteries of an e-vehicle that is environmentally friendly and does not contribute to pollution. 


\section{SJIF Impact Factor 2021: 8.013| ISI I.F.Value:1.241| Journal DOI: 10.36713/epra2016 ISSN: 2455-7838(Online) EPRA International Journal of Research and Development (IJRD) Volume: 6 | Issue: 6 | June 2021 - Peer Reviewed Journal}

- Dual-motor system and method for charging batteries of an e-vehicle that implements a cost and time effective mechanism. Dual-motor system and method for charging batteries of an e-vehicle with a satisfactory output which includes better options for charging the battery of the e- vehicle.

\section{METHODOLOGY}

When both batteries are externally charged, the connection of the front motors is automatically switched to the main motor controller unit. This means we're sending the generated voltage directly to the main motor, but the main motor's power consumption is high and the output from the front motors is low. As a result, the remaining power requirement is met by the first battery in this condition. As a result of these findings, the first battery consumption is significantly lower than that of other e-vehicle technologies.

Let's move on to the next condition. In the second condition, the first battery has been completely discharged; we're switching the battery connection, and now the second battery will provide power to the main motor and the front motor connection has also been switched to the charge controller of the first battery, and the first battery is charging while we're driving our vehicle. This occurs when the second battery is completely discharged; the first battery is charged to a maximum of 40-50 percent. This cycle will be repeated until both batteries have completely discharged. Then only we would require external charging. Under $2^{\text {nd }}$ condition when $1^{\text {st }}$ battery is charging, the motor uses $2^{\text {nd }}$ battery power for running.

In the $1^{\text {st }}$ condition when front motor output is given to rear and remaining power requirement is fulfilled by using $1^{\text {st }}$ battery. In the $2^{\text {nd }}$ condition when $1^{\text {st }}$ battery is discharged the front motor will charge the $1^{\text {st }}$ battery and rear motor is running on $2^{\text {nd }}$ battery.

This cycle will be continued until both batteries discharged completely. Then only we required external charging.

\section{CONCLUSION}

The output can be increased by $25 \%$ to $50 \%$. Because of the increased output on a single external charge, the distance between two charging stations will grow. As a result, the total number of charging points required will be reduced. Money will be saved, and the pollution at the charging station will be reduced. The charging speed of batteries will not change as a result of this, but batteries will charge while driving, saving time. When compared to a standard e-vehicle, this technique requires less external charging.

\section{REFERENCES}

1. Brenna, M., Foiadelli, F., Leone, C. et al. Electric Vehicles Charging Technology Review and Optimal Size Estimation. J. Electr. Eng. Technol. 15, 25392552 (2020). https://doi.org/10.1007/s42835-02000547-x

2. Ali Jokar, Barzin Rajabloo, Martin Désilets, Marcel Lacroix, Review of simplified Pseudo-two-Dimensional models of lithium-ion batteries, Journal of Power Sources, Volume 327, 2016, Pages 44-55, ISSN 03787753 ,

https://doi.org/10.1016/j.jpowsour.2016.07.036.(https:/ /www.sciencedirect.com/science/article/pii/S03787753 16308916)

3. Y. Liu, C. Hsieh and Y. Luo, "Search for an Optimal Five-Step Charging Pattern for Li-Ion Batteries Using Consecutive Orthogonal Arrays, " in IEEE Transactions on Energy Conversion, vol. 26, no. 2, pp. 654-661, June 2011, doi: 10.1109/TEC.2010.2103077

4. Castello CC, LaClair TJ, Maxey LC (2014) Control strategies for electric vehicle (EV) charging using renewables and local storage. In: Presented at the IEEE Transportation Electrification Conference and Expo (ITEC), Dearborn, MI, USA, Jun 18-15, 2014

5. Shiramagond T, Lee $W$ (2018) Integration of renewable energy into electric vehicle charging infrastructure. In: Presented at the 2018 IEEE International Smart Cities Conference (ISC2), Kansas City, MO, USA, Sept. 1619 , 7. https://doi.org/10.1109/ISC2.2018.8656981

6. Rivera, Sebastian, et al. "Electric vehicle charging station using a neutral point clamped converter with bipolar DC bus." IEEE transactions on Industrial Electronics 62.4 (2014): 1999-2009.

7. Feizi M, Beiranvand $R$ (2020) An improved phaseshifted full-bridge converter with extended ZVS operation range for EV battery charger applications. In: 2020 11th Power Electronics, Drive Systems, and Technologies Conference (PEDSTC), Tehran, Iran, 2020, $\quad$ pp. 16. https://doi.org/10.1109/PEDSTC49159.2020.908844 4

8. Zhao, Hong, et al. "Challenges of fast charging for electric vehicles and the role of red phosphorous as anode material." Energies 12.20 (2019): 3897.

9. Mortezaei A, Abdul-Hak M, Simoes MG (2018) A Bidirectional NPC-based level 3 EV charging system with added active filter functionality in smart grid applications. In: 2018 IEEE Transportation Electrification Conference and Expo (ITEC), Long Beach, CA, 2018, pp. 201206. https://doi.org/10.1109/ITEC.2018.8450196

10. Tu H, Feng H, Srdic S, Lukic S (2019) Extreme fast charging of electric vehicles: a technology overview. IEEE Trans Transport Electrific 5(4):861878. https://doi.org/10.1109/TTE.2019.2958709 